\title{
ACOMPANHAMENTO MENSAL DO CRESCIMENTO DA PARTE AÉREA EM CANAVIAL DE SEGUNDO CORTE
}

\author{
SEGATO, Silvelena Vanzolini ${ }^{1}$ \\ CARVALHO, Matheus Rodrigues Bressani de ${ }^{2}$
}

\begin{abstract}
RESUMO: A cana-de-açúcar é uma cultura de grande importância econômica para o Brasil e a busca de alternativas para o aumento da produtividade é constante. Com isso há necessidade de conhecer o seu crescimento visando tomar decisões técnicas adequadas em cada fase do ciclo da cultura. Assim, o trabalho teve o objetivo de conhecer o crescimento da parte aérea da primeira soca da cana-de-açúcar, variedade SP81-3250 através de avaliações mensais gerando curvas e estimando a produtividade com dados biométricos. O delineamento foi em blocos casualisados, com dez tratamentos (amostragens) e seis repetições. Foi analisado mensalmente, durante dez meses (de julho a abril), em propriedade em Cajuru/SP, características como: número de perfilhos, altura e diâmetro do colmo, comprimento e largura da folha +3 , área foliar, massa úmida e seca das folhas e dos colmos, bem como a estimativa de produtividade $\left(\right.$ t.ha $\left.^{-1}\right)$. Foi realizada análise de variância dos dados e as médias comparadas pelo teste de Tukey a $5 \%$ e ajustadas equações de regressão às médias. Os resultados demonstraram que para o número de perfilhos por metro o máximo foi de 27,3 e ocorreu em outubro, mas pela competição intraespecífica por elementos do meio apenas 9,8 perfilhos geraram colmos industrializáveis. O maior crescimento da parte aérea da cana está associado ao período de maior umidade e temperatura. O padrão de crescimento da parte aérea da maioria dos parâmetros avaliados coincide com uma curva sigmoide. A estimativa de produção usada superestimou a produtividade real pelo não desponte do colmo.
\end{abstract}

Palavras-chave: Ambiente de produção. Área foliar. Biometria. Estimativa de produção. Saccharum spp.

SUMMARY: The sugarcane is a culture that is being become enlarged and presenting great economic potential. In this way, they search each time alternative for the increase of the productivity. With this the necessity to know its growth to take decisions techniques adjusted in each phase of the cycle of the culture. Thus, the work had the objective to know the growth of the aerial part of the first ratoon cane, variety SP81-3250 through monthly evaluations generating curves and esteem the production with biometric data. The delineation was randomly blocks with ten treatments (samplings) and six repetitions. It was analyzed monthly from July to April for ten months in Cajuru, SP, Brazil, characteristic as number of tiller, height and diameter of stalk, length and width of the leaf, leaf area, cool and dry weight of leaves and stalk, as well as the estimate of production. It was carried through the analysis of variance of the data and the averages compared for the test of Tukey 5\%.The data had demonstrated that for the number of tiller the maximum was of 27.3 that it occurred in October, but for the intra-specific competition for elements of the way only 9,8 tiller had generated stalk industrialized. The biggest growth of the aerial part of the sugar cane is associated to the period of bigger humidity and temperature. The standard of growth of the aerial part of the majority of the evaluated parameters coincides with a curve sigmoid. The estimate of used production overestimated the real productivity for not the lopping of the tops of the stalk.

Keywords: Production environment. Leaf area. Biometric. Production estimate. Saccharum spp.

\section{INTRODUÇÃO}

O crescimento de uma planta caracteriza-se pelo aumento irreversível de tamanho e/ou massa e tem caráter quantitativo (NOGUEIRA et al., 2006). Wilhelm e Mcmaster (1995) complementam que o crescimento vegetal é o aumento irreversível em alguma dimensão física da planta com o tempo.

\footnotetext{
${ }^{1}$ Fundação Educacional de Ituverava

${ }^{2}$ Assistente técnico em pesquisa e desenvolvimento. NexSteppe Sementes (via unicampo) Brasil
} 
Santos (2006) relatou que a primeira etapa para avaliação da produção de uma variedade é a análise quantitativa de seu crescimento. Em cana-de-açúcar, as características varietais definem o número de colmos por planta, a altura e o diâmetro do colmo, o comprimento e a largura das folhas e a arquitetura da parte aérea, sendo a expressão destes caracteres muito influenciados pelo clima, pelo manejo e pelas práticas culturais utilizadas (RODRIGUES, 1995). Conforme Suguitani (2006), para o crescimento da cana-de-açúcar há vários componentes fenológicos como o número de perfilhos, a estatura dos colmos, densidade dos colmos que são características genéticas, mas que estão sujeitos a influências ambientais.

A temperatura do ar exerce grande influência no crescimento dos colmos. O crescimento torna-se lento em temperaturas abaixo de $25^{\circ} \mathrm{C}$. Para valores abaixo de $20^{\circ} \mathrm{C}$, o crescimento é praticamente nulo. Em termos de temperatura máxima, o crescimento seria lento acima de $35^{\circ} \mathrm{C}$ e nulo acima de $38^{\circ} \mathrm{C}$. Logo, deduz-se que a faixa ótima de temperatura, para o crescimento dos colmos, estaria entre $25^{\circ}$ e $35^{\circ} \mathrm{C}$ (RODRIGUES, 1995). Há também carta de aptidão climática para o Brasil, estabelecida por Camargo et al. (1977) e de aptidão edafoclimática (BRUNINI et al., 2008).

Teruel; Barbiere; Ferraro Júnior (1997); Oliveira et al. (2005) Civiero (2014) ressaltam que estudos de análise de crescimento em cana-de-açúcar possibilita a avaliação e a quantificação do crescimento durante o ciclo da cultura, em diferentes condições ambientais.

$\mathrm{O}$ crescimento de uma planta pode ser estudado por meio de medidas de diferentes tipos: lineares, superficiais, volumétricas, massa e número de unidades estruturais (BENINCASA, 2003). Os tipos de medidas a serem realizadas dependem, segundo Benincasa (2003) de aspectos como: objetivos do experimentador, disponibilidade de material a ser estudado, de mão-de-obra, de tempo do experimentador ou da equipe e de equipamentos para executar as medidas. Segundo Marafon (2012) a análise quantitativa do crescimento constitui-se numa ferramenta que possibilita a obtenção de informações a intervalos regulares, sem a necessidade de laboratórios e/ou equipamentos sofisticados, uma vez que as informações necessárias para sua determinação referem-se à massa da matéria seca (fitomassa) e à dimensão do aparelho fotossintetizante (área foliar) da planta.

Após a brotação inicia-se o desenvolvimento das folhas, que são responsáveis diretas pela transformação da energia solar em energia química através da fotossíntese. Cada colmo produz uma nova folha a cada 10 dias aproximadamente (GLASZIOU et al.,1965), e devido à senescência e queda das folhas mais velhas observa-se um número praticamente constante, de 8 a 10 folhas por colmo, após o fechamento do dossel (MACHADO, 1981).

O estudo da área foliar em cultivares de cana-de-açúcar permite correlacioná-la com o seu potencial produtivo, seja em massa seca, quantidade de açúcar ou taxas de crescimento. A folha é a estrutura responsável pela produção da maior parte dos carboidratos essenciais ao crescimento e desenvolvimento dos vegetais (HERMANN; CÂMARA, 1999).

O perfilhamento intenso da cana-de-açúcar é uma característica varietal desejável, segundo Tokeshi (1986), devido à maior proteção do solo, ao maior sombreamento, a redução do período de matocompetição, a redução de custos, ao maior nível de tolerância ao carvão e outras doenças e pragas que interferem no número de colmos industrializáveis.

A capacidade de perfilhamento e a sobrevivência dos perfilhos são aspectos importantes, pois são características que apresentam grande correlação com a produtividade agrícola (JAMES, 1971; MARIOTTI, 1971; SEGATO; MATTIUZ; MOZAMBANI, 2006).

O processo de perfilhamento é regulado pela auxina que é formada no topo e que desce em fluxo contínuo em direção à base. A auxina exerce, nesse caso, um duplo efeito: alongamento do colmo e o impedimento do desenvolvimento das gemas laterais (dominância apical). Com alta luminosidade o fluxo de auxina diminui e observa-se então decréscimo no grau de inibição das gemas laterais, o que 
resulta numa maior formação de perfilhos (CASAGRANDE, 1991).

Tokeshi (1986) ressalta que na curva de perfilhamento da cana-de-açúcar o seu ponto máximo ocorre, em geral, entre quatro e seis meses em cana-planta. Quando os perfilhos maiores atingem em torno de $50 \mathrm{~cm}$ de altura (até o colarinho da folha +1 ), inicia-se a concorrência por luz, água e nutrientes dentro e entre plantas. A tendência é de estabilizar-se o número de perfilhos e mais tarde, com o crescimento dos colmos dominantes, o seu número decresce com a eliminação dos mais fracos, doentes e mal posicionados.

Contudo, ao estudar as características ideais de crescimento de cultivares de cana-de-açúcar, Terauchi et al. (1999) e Terauchi e Matsuoka (2000) relatam que o rápido crescimento inicial, responsável por um fechamento do dossel, é uma característica importante para a cultura. Segundo os mesmos autores, o ideal seria um rápido crescimento dos colmos, promovendo fechamento do dossel, com um baixo número de perfilhos por área, assim, a massa seca dos perfilhos formados seria maior, devido à diminuição da competição intraespecífica. Nesse sentido Ramesh e Mahadevaswany (2000), estudando o efeito da seca nas diferentes fases do ciclo da cana-de-açúcar, constataram que os cultivares que perfilham menos, além de apresentarem menores porcentagens de mortalidade de perfilhos, apresentaram perfilhos com maior estatura, maior diâmetro de colmo e maior massa seca, indicando que estes cultivares tem correlação positiva com os cultivares mais produtivos.

Segundo Alvarez e Castro (1999) o perfilhamento da cana-crua não apresenta diferenças significativas que confirmem a influência negativa da palha na rebrota desta quando comparada ao perfilhamento da cana-queimada, indicando que a temperatura do solo coberto com palha não afeta o desenvolvimento da cultura.

Sendo a produtividade decorrente da massa e da quantidade de colmos por unidade de área, há relação da produtividade da cana-de-açúcar com a brotação dos toletes e o perfilhamento (CÂMARA, 1993; SEGATO; MATTIUZ; MOZAMBANI, 2006).

A análise de crescimento baseia-se fundamentalmente no fato de que cerca de $90 \%$, em média, da matéria seca acumulada pelas plantas, ao longo do seu crescimento, resultam da atividade fotossintética (BENINCASA, 1988; BENINCASA, 2003). O restante, da absorção de nutrientes minerais (BENINCASA, 2003; DUARTE, 2009). Assim, fatores como temperaturas elevadas em períodos de estresse hídrico causam a diminuição da área foliar, pois aceleram o processo de senescência das folhas verdes (INMAM-BAMBER, 2004). Neste sentido, Wahid (2004) acrescentou que em condições de estresses ambientais, genótipos sensíveis seriam mais prejudicados por reduzirem sua massa de folhas e sua área foliar.

Para se caracterizar a densidade da área foliar que cobre um terreno, comumente se utiliza o índice de área foliar (IAF) citado por Watson (1947), como sendo a área de folhas por unidade de terreno.

Segundo Machado et al. (1982), no início do ciclo da cultura o IAF é pequeno. Nessa fase, apresenta um crescimento lento, aumentando, rapidamente, até atingir um valor máximo. A partir daí permanece, praticamente, constante ou pode diminuir em condições climáticas desfavoráveis. O aumento do IAF ocorre em função tanto do aumento do número de folhas por colmo, como do aumento da área foliar individual.

Existe uma significativa associação entre a produtividade da cultura e a superfície total fotossinteticamente ativa representada pelo IAF (IRVINE, 1975). Segundo Hesketh e Baker (1967), o valor do IAF está intimamente associado com a quantidade de luz absorvida e com a fotossíntese total. Ainda com relação ao IAF, Gascho e Shih (1983) notaram que o valor máximo para a cultura da cana-deaçúcar foi alcançado aos seis meses de idade da planta, enquanto que se obteve o máximo de colmos aos cinco meses de idade. O aumento do IAF prenuncia alta produção de fotossintatos e alta 
produção de açúcares.

Leme; Maniero e Guidolin (1984) citam que o IAF é efetivo para avaliar o rendimento final, sendo que os maiores valores durante o ciclo de desenvolvimento estariam relacionados com a maior produção final de colmos de cana. Nesse sentido, o conhecimento da dinâmica de crescimento da área foliar, bem como da arquitetura do sistema foliar, em diferentes cultivares de cana-de-açúcar, pode permitir melhor compreensão das relações destas características com o rendimento final.

Segundo Chang (1968), o ideal é que o IAF máximo ocorra sob condições climáticas satisfatórias à fotossíntese.

De acordo com Rodrigues (1995), a área foliar é um dos mais importantes parâmetros da análise de crescimento, podendo ser medida através de aparelhos específicos ou de fórmulas que permitem sua estimativa. A escolha da folha a ser usada na mensuração, deve seguir a numeração proposta por Van Dillewijn (1952) que geralmente utiliza a folha +3 , considerada adulta.

Machado (1987) comenta que a mortalidade dos colmos coincide com o período em que o IAF aumenta rapidamente sugerindo, que além da competição por água e nutrientes, o sombreamento é um dos fatores mais importantes na determinação deste comportamento.

De acordo com Maule; Mazza e Martha Jr (2001), a disponibilidade de água no solo governa a produção vegetal, sendo que sua falta ou seu excesso afeta o desenvolvimento da área foliar da cana-deaçúcar. Miocque (1999) e Ido (2003) relatam que o período de maior crescimento da área foliar pode ser observado entre os meses de dezembro a março.

O crescimento da parte aérea engloba o crescimento do caule e das folhas. As folhas mais velhas, ao secarem, podem ou não se destacar da bainha. A longevidade delas é característica específica de cada variedade. Uma folha tem durabilidade média de 60 a 90 dias. O tempo decorrido entre o aparecimento de duas folhas subsequentes é de 5 a 8 dias. Folhas não caduca constituem um fator muito importante no mecanismo de armazenamento do açúcar pela planta, que é utilizado na formação de celulose e nos processo de respiração e maturação da mesma (CESNIK; MIOCQUE, 2004).

Machado et. al. (1982), Rocha (1984) e Prado (1988) observaram que durante o ciclo da cana-deaçúcar ocorre queda do número de colmos, com o máximo obtido nos meses de setembro, outubro e novembro e com queda brusca em janeiro, desde então decrescendo mais lentamente até a época de colheita. Além do efeito genético, isso varia com a época de plantio ou colheita, neste segundo caso para as soqueiras, e de inúmeros outros fatores ambientais, direta ou indiretamente.

Miocque (1999) e Barbosa et al. (2002) relatam que a estatura de colmos tem correlação positiva com a produtividade. Ido (2003), ao estudar cultivares de cana-de-açúcar, plantados em rizotron, observou que o período de maior crescimento em estatura para a cultura ocorreu entre os meses de dezembro a março. Portanto, nos meses mais quentes como cita Casagrande (1991). Esses resultados confirmam os observados por Miocque (1999), que identificou o período de novembro a fevereiro, como sendo o período de maior crescimento para a cultura.

Segundo Machado et al. (1982) e Oliveira (2004) no aumento da matéria seca da cana e de suas folhas, observa-se três fases: 1- fase inicial de crescimento lento; 2- fase de crescimento rápido e 3- fase final em que o crescimento é novamente lento.

A análise biométrica é de grande importância na obtenção de dados de crescimento de uma cultura, uma vez que este é avaliado por meio de observações das variações em algum aspecto, geralmente morfológico, em função do acúmulo de material oriundo do processo fotossintético (BENINCASA, 1988) e pode ser realizada por meio de medidas de dimensões lineares como a altura da planta, o comprimento e a largura de unidades estruturais morfológicas ou anatômicas, número de unidades estruturais e medidas de superfície como, por exemplo, medidas de área foliar. O desenvolvimento da área foliar é crítico ao 
estabelecimento da cultura, ao fechamento do dossel e à maximização da interceptação da radiação em busca da produtividade da cultura (SINCLAIR et al., 2004).

Aplicada à cana-de-açúcar, a análise biométrica permite segundo Rodrigues (1995), avaliar o crescimento da cultura em seu ambiente de cultivo, proporcionando a identificação dos fatores que influenciam no seu desenvolvimento. Além disso, gera informações que poderão vir a contribuir com modelos computacionais de simulação de crescimento da cultura, os quais são indispensáveis às melhorias de manejo, como também à redução de riscos inerentes às dúvidas técnicas relacionadas à expansão da cultura, segundo Sinclair et al. (2004), e que tem sua importância calcada no fato de que estudos desse tipo, sobre a cultura da cana-de-açúcar, serem praticamente inexistentes fora de unidades de produção e, portanto, pouco divulgados na comunidade científica.

Dessa forma, o trabalho teve o objetivo de conhecer o crescimento da parte aérea em canavial de segundo corte, variedade SP81-3250, através de avaliações mensais gerando curvas e estimando a produção com dados biométricos.

\section{MATERIAL E MÉTODO}

$\mathrm{O}$ experimento foi conduzido em área comercial, em cana-soca, em Cajuru (SP), localizado a $21^{\circ} 16^{\prime} 38^{\prime}$ " S e $31^{\circ} 03^{\prime} 02^{\prime \prime} \mathrm{O}$, com altitude de 750m. A região apresenta clima Tropical Temperado, segundo a classificação de Koëppen, com temperatura média anual de $22,5^{\circ} \mathrm{C}$ e precipitação pluvial total do ano de $1.300 \mathrm{~mm}$. Tendo a área um Neossolo Quartzarênico (textura arenosa).

Para o ensaio foi usada a primeira rebrota da cana-de-açúcar, variedade SP81-3250, colhida no dia 15 de junho e com início de brotação em sete dias após o corte (DAC). Avaliou-se a textura do solo em três profundidades, coletando-se seis amostras simples, com trado holandês, em cada parcela, em cada profundidade. Utilizando-se de baldes identificados, as amostras foram homogeneizadas (amostra composta), para cada uma das três profundidades: 0-20, 20-40 e 40-60 cm, do local de condução do experimento, como constam na Tabela 1.

Pelos resultados obtidos confirmou-se tratar de um solo arenoso (Tabela 1). As amostras de solos foram retiradas no dia 18 de setembro, após locar o experimento e iniciar as avaliações mensais.

Tabela 1. Análise textural do solo utilizado no experimento sobre o crescimento da cana-soca SP81-3250, na camada de 0-20, 20-40 e 40-60 cm de profundidade. Laboratório de solos, do Centro Universitário Moura Lacerda, Ribeirão Preto, SP.

\begin{tabular}{|c|c|c|c|}
\hline \multirow[t]{2}{*}{ Composto } & \multicolumn{3}{|c|}{ Porcentagem (\%) } \\
\hline & $0-20 \mathrm{~cm}$ & $20-40 \mathrm{~cm}$ & $40-60 \mathrm{~cm}$ \\
\hline Areia total & 92,56 & 92,59 & 92,51 \\
\hline Silte & 0,21 & 0,21 & 0,22 \\
\hline Argila & 7,23 & 7,2 & 7,27 \\
\hline Classificação textural & Arenosa & Arenosa & Arenosa \\
\hline
\end{tabular}

Fonte: Elaborado pelo autor

O delineamento foi o de blocos casualizados (DBC), com seis repetições. Para cada variável analisada, as avaliações mensais serviram de tratamentos, portanto dez tratamentos (amostragens) e seis repetições (seis pontos de 1 metro linear).

O experimento foi delineado com 10 parcelas sendo uma parcela escolhida por sorteio para cada mês e uma destas para estimar a produção (Figura 1 A). Cada parcela continha cinco linhas espaçadas de $1,5 \mathrm{~m}$ e com $10 \mathrm{~m}$ de comprimento. Para as avaliações foram tomadas seis pontos de $1 \mathrm{~m}$ linear dentro da 
parcela útil (Figura 1B). A parcela útil foi formada descartando-se uma linha lateral de cada lado (bordadura) e um metro no início e no fim de cada linha. Sendo os seis pontos retirados das linhas centrais de cada parcela, a fim de não interferir no crescimento da planta das parcelas adjacentes, conforme esquema da Figura 1B.

Figura 1. Croqui do ensaio (A) e esquema representando a parcela útil (B) de cada parcela do ensaio sobre o crescimento da parte aérea da primeira soca da cana-de-açúcar, SP81-3250. Cajuru, SP.

A

\begin{tabular}{|c|c|c|c|c|}
\hline$* \mathrm{P}_{6}$ & $\mathrm{P}_{2}$ & $\mathrm{P}_{5}$ & $\mathrm{P}_{9}$ & \\
\hline $\mathrm{P}_{1}$ & $\overline{P_{3}}$ & & $\begin{array}{c}\mathrm{P}_{10} \\
\text { Producão final }\end{array}$ & \\
\hline & $\mathrm{P}_{4}$ & $\mathrm{P}_{8}$ & & $\mathrm{P}_{7}$ \\
\hline
\end{tabular}

B

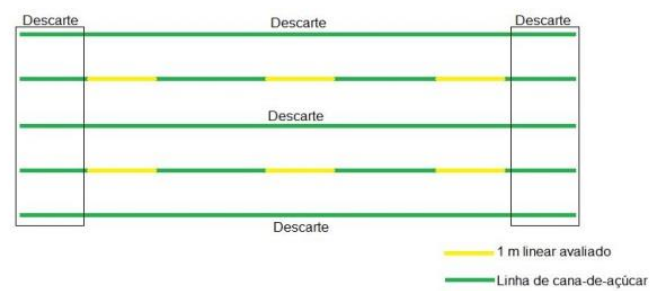

*Em que: $\mathrm{P}=$ parcela; $1,2 \ldots 10$ = sequência de coleta das amostras. Produção final = parcela que foi usada para estimar produtividade de massa da cultura.

Fonte: Elaborado pelo autor

Com parte das amostras utilizadas para classificar a textura do solo, determinou-se a composição química do mesmo, conforme a Tabela 2.

Tabela 2. Análise química do solo $(0-20,20-40$ e 40-60 $\mathrm{cm}$ de profundidade), em que foi implantado o experimento sobre o crescimento da parte aérea em cana-soca. Laboratório de análise de solo e foliar de Ribeirão Preto/SP. RIBERSOLO. Ribeirão Preto/SP.

\begin{tabular}{|c|c|c|c|}
\hline \multirow[t]{2}{*}{ Elementos } & \multicolumn{3}{|c|}{ Concentração } \\
\hline & $0-20 \mathrm{~cm}$ & $20-40 \mathrm{~cm}$ & $40-60 \mathrm{~cm}$ \\
\hline $\mathbf{P H}$ & $5.2{\mathrm{~g} . \mathrm{dm}^{-3}}^{-3}$ & 4.3 g.dm ${ }^{-3}$ & 4.3 g. $\mathrm{dm}^{-3}$ \\
\hline MO & $12 \mathrm{~g}^{\mathrm{dm}}{ }^{-3}$ & 9 g. $\mathrm{dm}^{-3}$ & 9 g.dm ${ }^{-3}$ \\
\hline $\mathbf{P}$ & $7 \mathrm{mg} \cdot \mathrm{dm}^{-3}$ (resina) & $5 \mathrm{mg} \cdot \mathrm{dm}^{-3}$ (resina) & $5 \mathrm{mg} \mathrm{dm}^{-3}$ (resina) \\
\hline $\mathbf{K}$ & $0.6 \mathrm{mmol}^{\mathrm{dm}}{ }^{-3}$ & 0.3 mmolc. $\mathrm{dm}^{-3}$ & 0.5 mmolc. $\mathrm{dm}^{-3}$ \\
\hline $\mathbf{C a}$ & 9 mmol. $\mathrm{dm}^{-3}$ & 4 mmolc. $\mathrm{dm}^{-3}$ & 4 mmolc. $\mathrm{dm}^{-3}$ \\
\hline Mg & $3 \mathrm{mmol} . \mathrm{dm}^{-3}$ & $1 \mathrm{mmolc} \cdot \mathrm{dm}^{-3}$ & $1 \mathrm{mmolc} \cdot \mathrm{dm}^{-3}$ \\
\hline CTC & $26 \mathrm{mmol}^{\mathrm{dm}} \mathrm{dm}^{-3}$ & 22 mmolc. $\mathrm{dm}^{-3}$ & 22 mmolc. $\mathrm{dm}^{-3}$ \\
\hline V\% & $50.4 \%$ & $25.9 \%$ & $24.8 \%$ \\
\hline $\mathbf{H}+\mathbf{A l}$ & 13 mmolc. $\mathrm{dm}^{-3}$ & 16 mmolc. $\mathrm{dm}^{-3}$ & 17 mmolc. $\mathrm{dm}^{-3}$ \\
\hline
\end{tabular}

Fonte: Elaborado pelo autor

Pelos dados obtidos (Tabela 2), verificou-se que se tratava de um solo com pH baixo a médio em superfície e baixo a muito baixo em subsuperfície. A matéria orgânica (MO), a CTC e o fósforo (P) disponível apresentava teor baixo em todo perfil do solo. O V\% era médio em superfície e baixo em subsuperfície. A acidez potencial $(\mathrm{H}+\mathrm{Al})$ era baixa no perfil do solo. Predominava níveis baixos para o potássio $(\mathrm{K})$ em todo perfil do solo, e, para cálcio $(\mathrm{Ca})$ e magnésio $(\mathrm{Mg})$ os níveis eram baixos em superfície e muito baixos em subsuperfície.

Houve o controle em pós-emergência de plantas daninhas na cana-soca. As espécies de maior incidência foram o capim-colchão (Digitaria spp.), corda-de-viola (Ipomoea grandifolia) e buva (Conyza spp.). Foram utilizados os herbicidas: MSMA, diuron + hexazinona e 2,4 D amina. Aos 13 dias após o corte (DAC) da cana-planta foram distribuídos 4,13 t.ha ${ }^{-1}$ de cama-de-frango em área total, comimplemento usado na distribuição de calcário, substituindo a adubação química. Entretanto, não se 
realizou a análise do resíduo, mas segundo Rezende, Curi e Santana (2004) a adubação orgânica possui vantagens, dentre as quais: efeitos condicionadores (favorecem a floculação e agregação das partículas, a aeração e a estrutura do solo), aumentam a capacidade de retenção de água e a CTC (capacidade de troca catiônica) do solo, tem efeitos sobre os nutrientes (aumentam sua disponibilidade por meio de processos de mineralização e contribuem para a diminuição da fixação de $\mathrm{P}$ no solo) e possuem efeitos sobre os microrganismos do solo (sendo fonte de nutrientes e energia). Aos 90 DAC realizou-se a tríplice operação.

As dez épocas de avaliações foram consideradas como tratamentos na determinação de características de interesse, visando acompanhar o crescimento da parte aérea da cana-soca, SP81-3250 aos: $30 ; 66 ; 93 ; 121 ; 147 ; 175 ; 208 ; 252 ; 273 ; 300$ dias após a colheita (DAC), respectivamente 15/07; $21 / 08 ; 18 / 09 ; 16 / 10 ; 12 / 11 ; 10 / 12 ; 13 / 01 ; 27 / 02 ; 18 / 03$ e 14/04.

Foram compilados dados do Centro integrado de informações agrometeorológicas (CIIAGRO, 2017) das condições de temperatura e precipitação, em Cajuru, SP, no mês anterior e durante o experimento.

Foi avaliado o número de perfilhos através da contagem direta do número de perfilhos em um metro linear, a partir da terceira amostragem. A altura dos colmos $(\mathrm{em} \mathrm{cm})$ foi mensurada da base até a inserção da folha +1 , com auxílio de fita métrica. O diâmetro de colmo (em mm), com auxílio de paquímetro, foram medidos no primeiro $1 / 3$ do comprimento do colmo da base para a ponta (LANDELL; SILVA, 1995).

O número de folhas ativas foi avaliado e considerado as que possuíam o dewlap (colarinho) visível. O comprimento da folha $+3(\mathrm{em} \mathrm{cm})$ foi mensurado na região do "dewlap" até a ponta, a partir da segunda avaliação. A largura da folha $+3(\mathrm{em} \mathrm{cm})$ medida na parte mais larga da mesma folha que foi usada para determinar o comprimento, também a partir da segunda avaliação. Área foliar $\left(\mathrm{em} \mathrm{cm}^{2}\right)$ : a partir da segunda avaliação calculou-se a área foliar através da medição de largura e comprimento da folha +3, segundo metodologia de Hermann e Câmara (1999), dada pela fórmula: $\mathrm{AF}=\mathrm{C} \times \mathrm{L}$ x 0,75 x $(\mathrm{N}+2)$, em que: C é o comprimento da folha +3 ; $\mathrm{L}$ é a largura da folha $+3 ; 0,75$ é o fator de correção para área foliar da cultura e $\mathrm{N}$ é o número de folhas abertas com pelo menos $20 \%$ de área verde e 2 o fator de ponderação para as folhas que ainda não estão totalmente expandidas.

Massa úmida e seca da folha foi determinada, a massa úmida (pesada em uma balança de $5 \mathrm{~g}$ de precisão) e seca (em estufa de ar forçado a $70^{\circ} \mathrm{C}$ até peso constante) das folhas ativas, das folhas senescentes (com mais de $80 \%$ da área foliar seca) e das folhas totais, em que todas as folhas foram retiradas dos perfilhos, incluindo a folha +3 (usada para determinar o comprimento e largura).

Massa úmida e seca do colmo (em cada metro), os colmos foram cortados rentes ao solo e pesados já sem folhas, determinando-se a massa fresca em balança de $5 \mathrm{~g}$ de precisão. A massa seca foi calculada a partir do peso do material fresco picado, após secagem em estufa de ar forçado a $70^{\circ} \mathrm{C}$, até peso constante.

Foi estimada a produtividade, em toneladas de cana por hectare (TCH), com amostras de seis pontos da décima parcela útil, aos 300 dias após o corte (DAC), em 14/04, utilizando-se a fórmula citada por Bidoia e Bidoia (2008): $\mathrm{TCHe}=\mathrm{D}^{2}$ X C X H X (0,007854/E), em que: $\mathrm{TCHe}=$ tonelada de cana por hectare (valor estimado); $\mathrm{D}=$ diâmetro do colmo $(\mathrm{cm}) ; \mathrm{E}=$ espaçamento entre sulcos $(\mathrm{m}) ; \mathrm{C}=\mathrm{colmos}$ por metro; $\mathrm{H}=$ altura média do feixe de colmos $(\mathrm{cm})$. Foram usados comparativamente os dados fornecidos pela usina sobre a cana colhida do proprietário.

Ao final foi realizada análise de variância dos dados e as médias foram comparadas pelo teste de Tukey a 5\% de probabilidade. O programa usado foi o Statsoft (2007). Também para as médias foram ajustadas equações de regressão polinomial. 


\section{RESULTADO E DISCUSSÃO}

A precipitação acumulada no mês anterior e durante a condução do experimento (Figura 2) foi de $1868,1 \mathrm{~mm}$ e uma temperatura média no período que foi de $22,4^{\circ} \mathrm{C}$.

Houve chuva em todos os meses (Figura 2), em menor volume em junho e julho de 2009 e abril de $2010(57,7 ; 46,4$ e 44,8mm, respectivamente). De agosto a março volumes que oscilaram de 111,7mm (agosto) a $471,6 \mathrm{~mm}$ (dezembro). De junho a agosto temperatura inferior ou igual a $20^{\circ} \mathrm{C}$. De setembro a março variação de $22,5^{\circ} \mathrm{C}$ (setembro) a $25,1^{\circ} \mathrm{C}$ (novembro), com destaque para fevereiro $\left(25^{\circ} \mathrm{C}\right)$ e caindo em abril para $21,9^{\circ} \mathrm{C}$

Figura 2. Dados de temperatura média $\left({ }^{\circ} \mathrm{C}\right)$ e precipitação $(\mathrm{mm})$, em Cajuru, SP, no mês anterior e nos meses de condução do experimento sobre crescimento da cana-soca (Fonte: CIIAGRO, 2017).

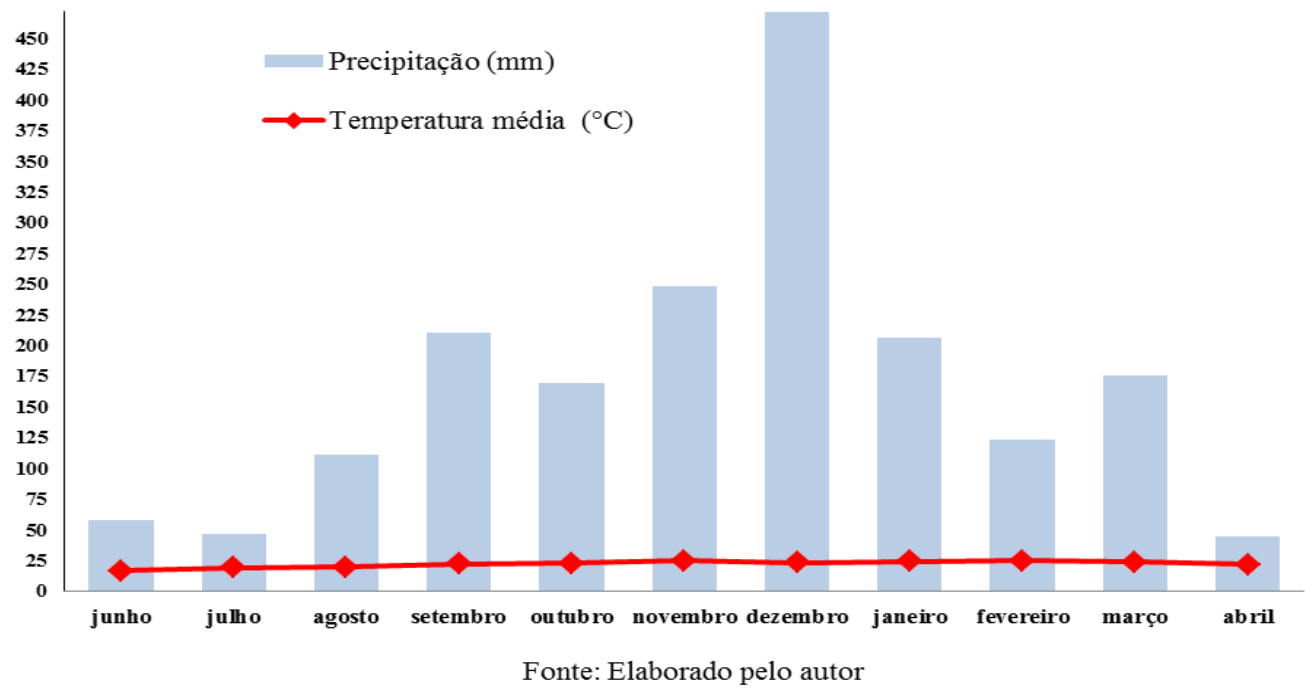

Inicialmente, primeiros 60 dias após colheita - DAC (julho/agosto) o número de perfilhos avaliados foi pequeno, aproximadamente dez para cada repetição, a partir de setembro começou a avaliação em um metro linear, verificando-se aumento no número de perfilhos (Figura 3) até atingir o valor máximo de 27,3 perfilhos por metro em outubro (121 DAC). Esses dados confirmam a constatação de Segato; Mattiuz e Mozambani (2006) que relatam que na fase de intenso perfilhamento da cana-deaçúcar algumas variedades produzem 25 ou mais colmos.

Nos dados da Figura 3 a fase de intenso perfilhamento ocorreu de setembro a dezembro, dos 93 aos 175 DAC. Machado et al. (1982), Rocha (1984) e Prado (1988) também observaram que durante o ciclo da cana-de-açúcar ocorre queda do número de colmos, com o máximo obtido nos meses de setembro, outubro e novembro e com queda brusca em janeiro, desde então decrescendo mais lentamente até a época de colheita, assim como verificado no ensaio realizado em Cajuru, SP (Figura 3).

Na última avaliação a média foi de 9,8 perfilhos por metro linear (Figura 3) demonstrando que houve competição entre os perfilhos por água, luz, nutrientes e outros elementos do meio e assim boa parte destes morreu e os sobreviventes formaram os colmos industrializáveis. Dados que concordam com o relato de outros autores ( CÂMARA, 1993; TOKESHI, 1986; SEGATO; MATTIUZ; MOZAMBANI, 2006). 
Figura 3. Dados médios (A) e curva de regressão (B) referente ao número de perfilhos por metro linear, em cana-soca, SP81-3250. Cajuru, SP.
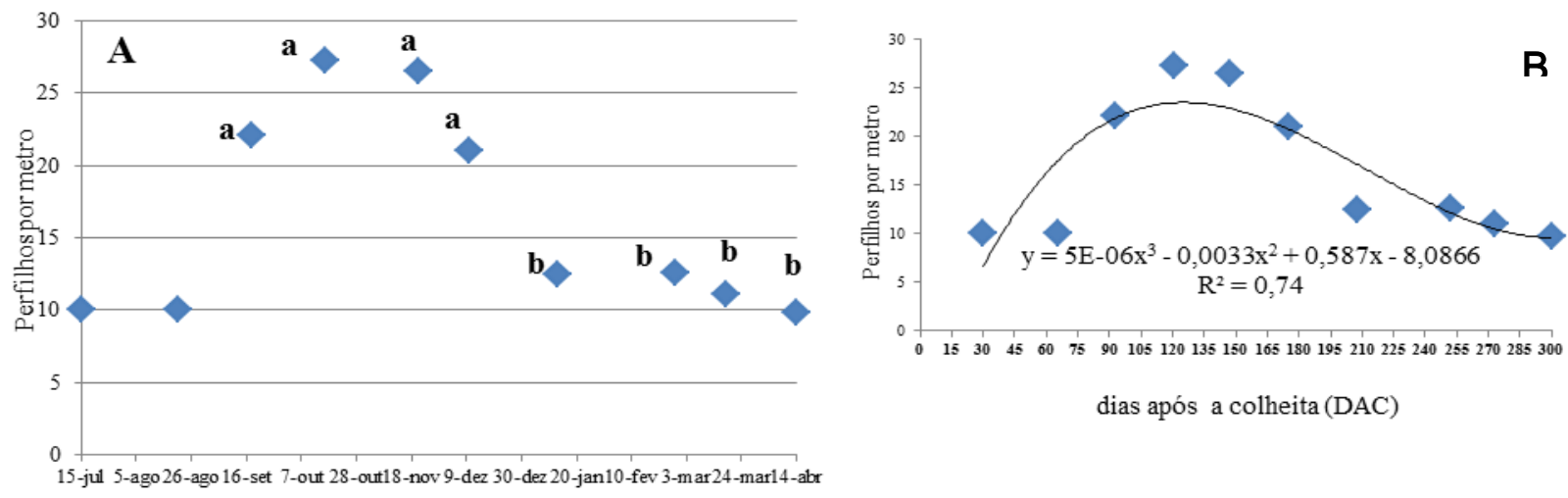

Fonte: Elaborado pelo autor

Os pontos referentes as amostragens mensais descrevem uma curva sigmóide para a altura da cana (Figura 4), inicialmente crescendo lentamente até setembro, aos 93DAC (em que a cana está na fase inicial de perfilhamento intenso) e depois de forma mais intensa até fevereiro (aos 252 DAC) e novamente crescendo mais lentamente a partir de fevereiro (252 DAC) até abril (300 DAC). Dados semelhantes aos verificados por Berton (2014), também em cana-soca, que descreve três fases de crescimento: lenta até 122 DAC, rápida até 248 DAC e lenta dos 248 aos 369 DAC. Tais dados, representados pela Figura 4 comparam-se com a bibliografia citada por Rodrigues (1995), em que é relatado que a cana tem um crescimento mínimo de maio a setembro, sendo que a partir daí inicia-se o período chuvoso que é quando a cana-de-açúcar tem um maior desenvolvimento até janeiro e em seguida há novamente estabilização em seu crescimento o que contribui para a acumulação gradativa de açúcares.

Sabe-se que as relações hídricas desempenham papel importante na elongação dos perfilhos e no crescimento final dos colmos da cana-de-açúcar. A elongação celular e o crescimento da cultura são intimamente ligados aos níveis de umidade do solo, quanto maior a disponibilidade hídrica do solo maior o crescimento da cultura (SILVA; CATO; COSTA, 2010). Miocque (1999) e Barbosa et al. (2002) relatam que a estatura de colmos tem correlação positiva com a produtividade. Miocque (1999) identificou o período de novembro a fevereiro, como sendo o período de maior crescimento para a cultura. Ido (2003) observou que o período de maior crescimento em estatura para a cultura ocorreu entre os meses de dezembro a março. Portanto, nos meses mais quentes e úmidos como citou Casagrande (1991). Esses resultados corroboram os observados nesse trabalho, em Cajuru/SP.

Figura 4. Dados médios (A) e curva de regressão (B) referente ao crescimento em altura $(\mathrm{cm})$ em canasoca, SP81-3250. Cajuru, SP.
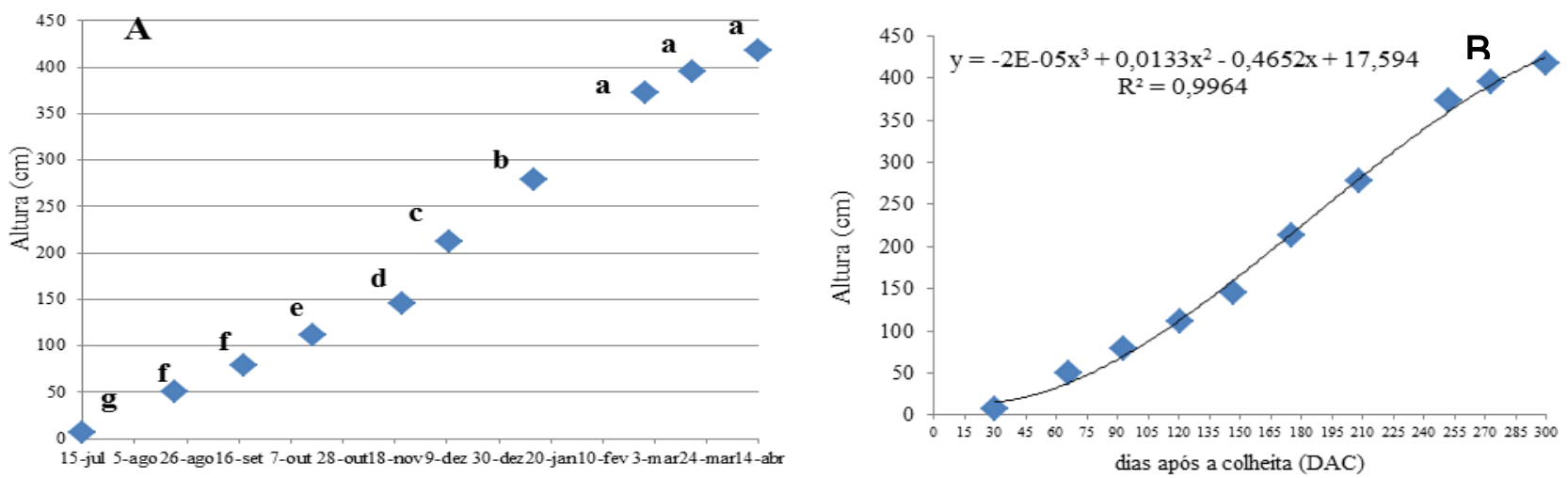

Fonte: Elaborado pelo autor 
No gráfico que expressa os valores de diâmetro (Figura 5), em função dos diferentes estágios de crescimento dos perfilhos, que compõe o um metro amostrado, inicialmente o diâmetro aumenta progressivamente até dezembro, aos $175 \mathrm{DAC}$, que marca o final da fase de perfilhamento intenso (Figura 3), a partir desta data até o final do ciclo da cultura já se observa estabilização do diâmetro.

Figura 5. Dados médios (A) e curva de regressão (B) referente ao crescimento em diâmetro do colmo (mm) em cana-soca, SP81-3250. Cajuru, SP.
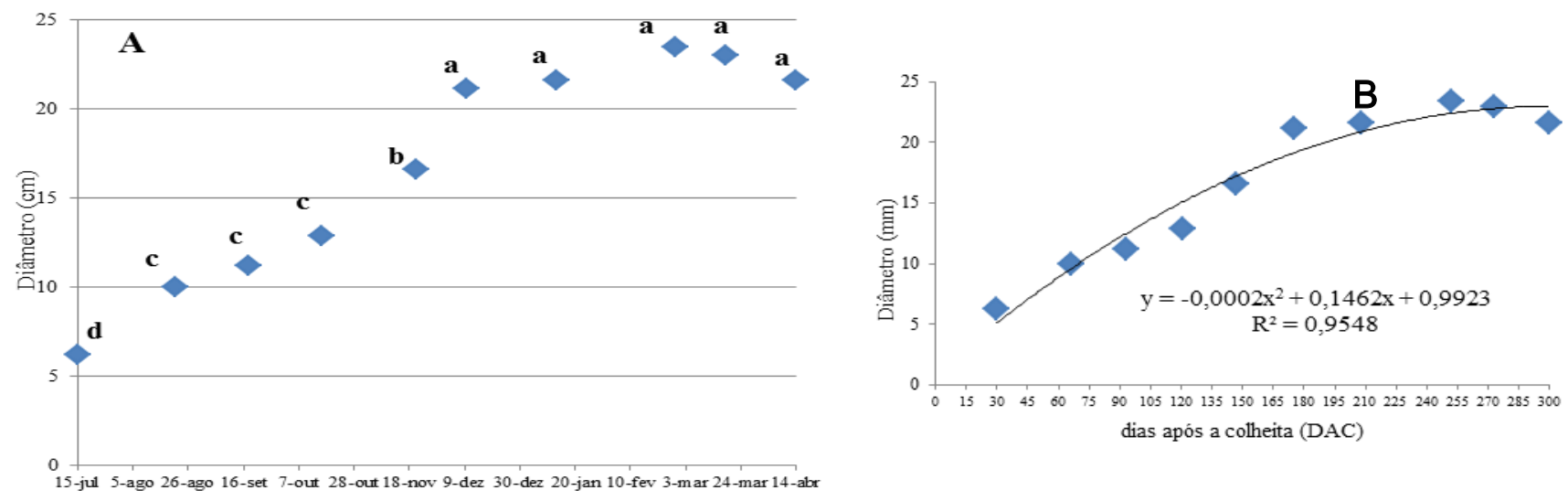

Fonte: Elaborado pelo autor

O máximo de folhas ativas $(6,6)$ foi atingido em fevereiro, aos 252 DAC (Figura 6), embora com valores que não diferiram de janeiro e março. Miocque (1999) e Ido (2003), relatam que o período de maior crescimento da área foliar pode ser observado entre os meses de dezembro a março. Folhas não caduca constituem um fator muito importante no mecanismo de armazenamento do açúcar pela planta, que é utilizado na formação de celulose e nos processo de respiração e maturação da mesma (CESNIK; MIOCQUE, 2004). Em abril, com redução na precipitação e temperatura (Figura 2) e tratando-se de um solo arenoso (Tabela 1) e pobre (Tabela 2) iniciou-se a redução do número das folhas ativas.

O número inicial de folhas ativas (Figura 6) foi em média 1,5 no primeiro mês (julho), este número aumentou em agosto para 3,3 ficando estável até novembro quando novamente aumentou até fevereiro $(6,6)$ e decresceu em março $(5,8)$ e abril (5) devido, provavelmente, ao ambiente restritivo. Devido à senescência e queda das folhas mais velhas observa-se um número praticamente constante, de 8 a 10 folhas por colmo, após o fechamento do dossel (MACHADO, 1981). No experimento o número de folhas ativas foi de no máximo 6,6 (Figura 6).

Figura 6. Dados médios (A) e curva de regressão (B) referente ao número de folhas ativas resultantes do crescimento da cana-soca, SP81-3250. Cajuru, SP.
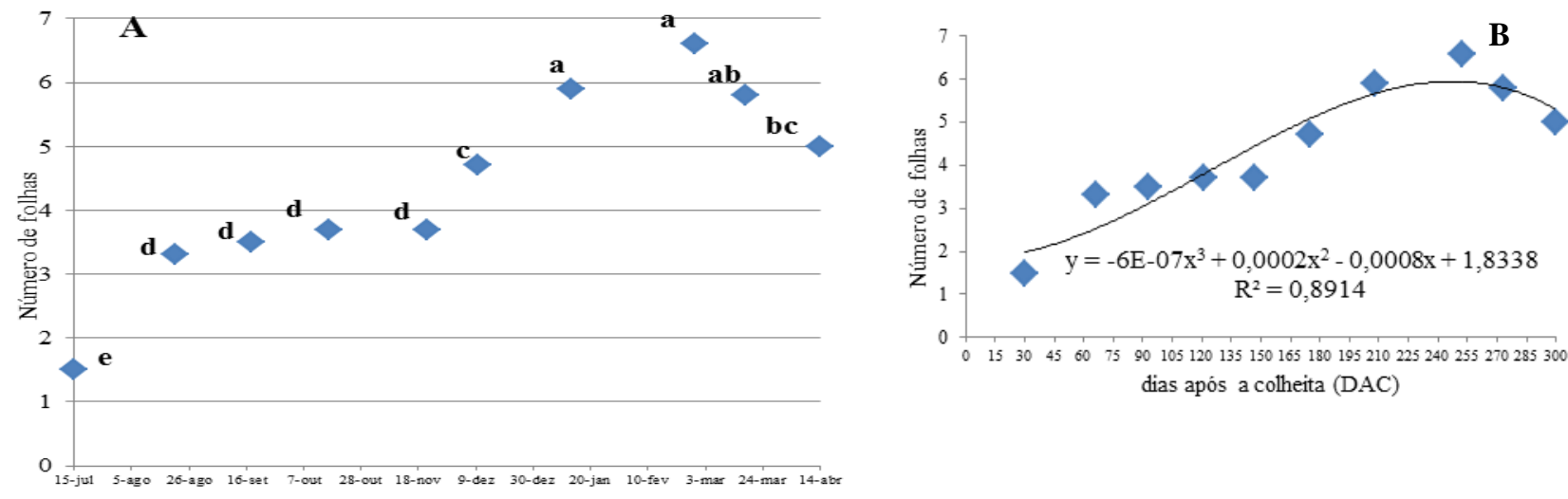

Fonte: Elaborado pelo autor 
Observa-se que o ganho de massa fresca das folhas ativas (Figura 7) foi crescente até o mês de dezembro, em que a umidade proporcionada pela grande precipitação do mês (Figura 2) levou a um pico nessa medida, tendo demonstrado que os valores tornaram-se praticamente estáveis entre os meses de novembro até abril (Figura 7).

Figura 7. Dados médios (A) e curva de regressão (B) referente à massa úmida (g) das folhas ativas em $1 \mathrm{~m}$ linear, SP81-3250, em cana-soca. Cajuru, SP.
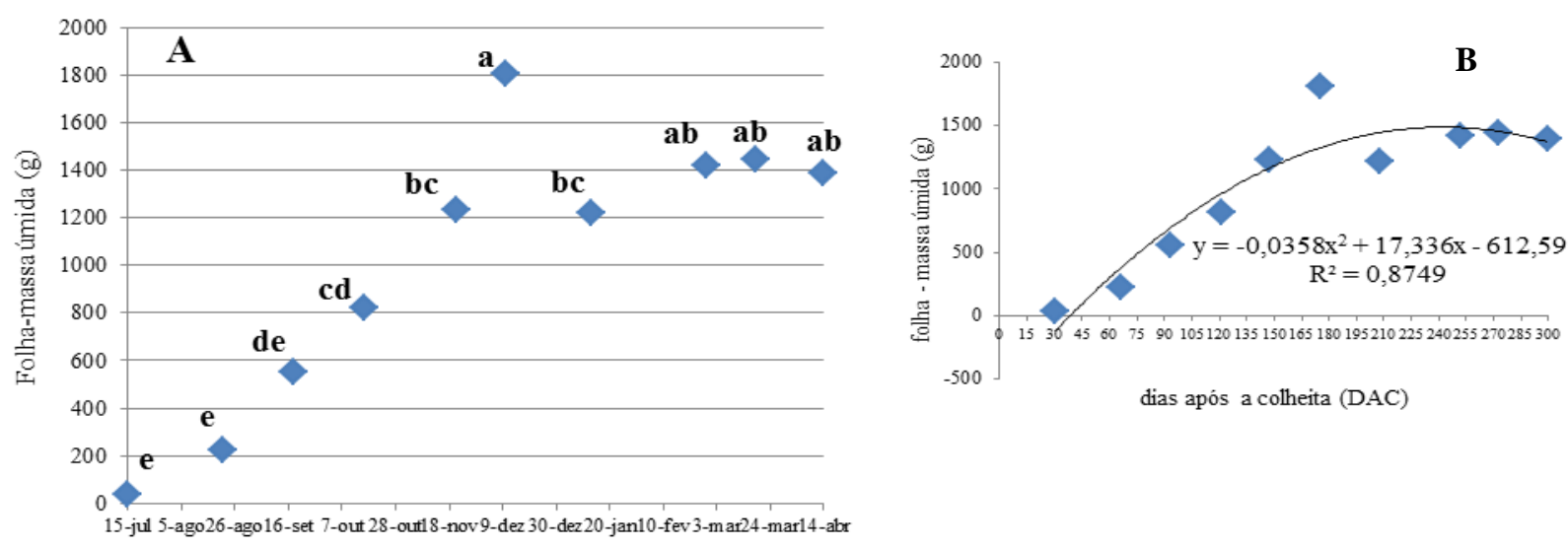

Fonte: Elaborado pelo autor

Pelos valores de massa seca das folhas ativas (Figura 8) observa-se que o ganho foi menor e estatisticamente semelhante entre julho a agosto (em que as condições ambientais foram mais restritivas) aumentando gradativamente até o final da avaliação (abril).

Figura 8. Dados médios $(\mathrm{A})$ e curva de regressão $(\mathrm{B})$ referente à massa seca $(\mathrm{g})$ das folhas ativas em $1 \mathrm{~m}$ linear da cana-soca, SP81-3250. Cajuru, SP.
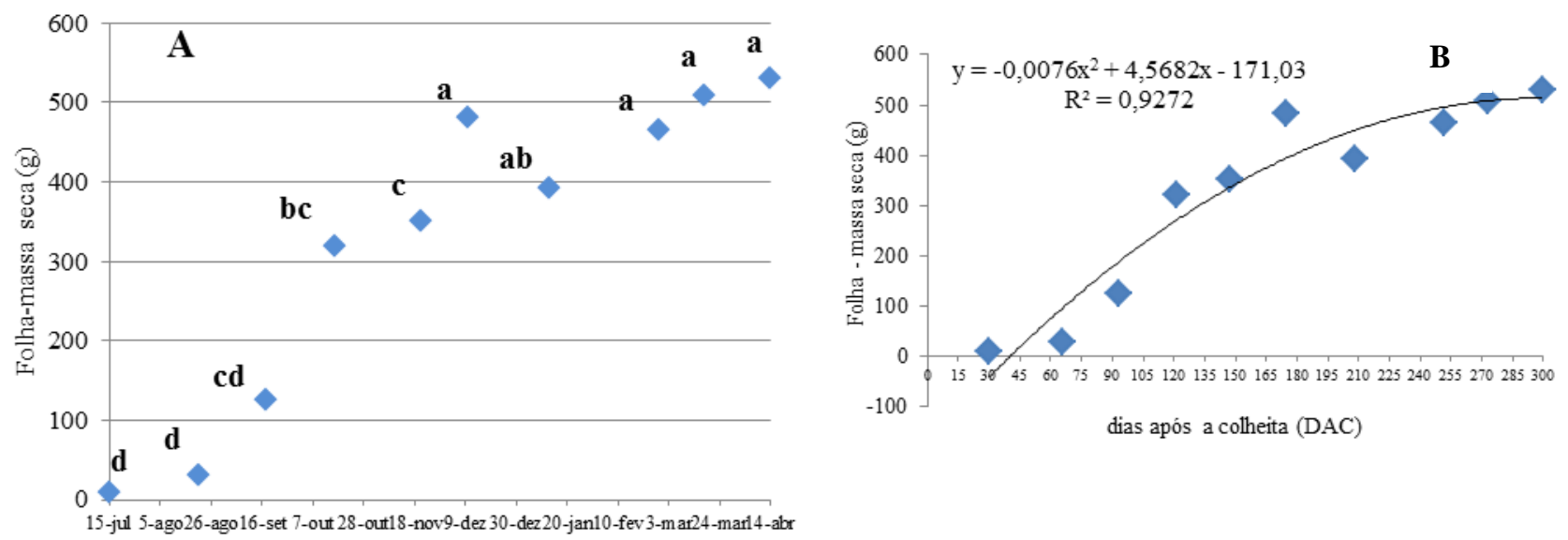

Fonte: Elaborado pelo autor

Apenas em novembro foi possível detectar folhas senescentes na cultura (Figura 9 e 10). Essas folhas aumentaram com o decorrer do ensaio, mas em função provavelmente da precipitação do período (Figura 2), não foi possível ajustar uma equação de regressão consistente para massa úmidas das folhas senescentes (Figura 9), diferentemente da massa seca dessas folhas (Figura 10), quando se elimina o fator umidade, e, é visível o aumento linear na massa seca das folhas senescentes da cana-soca de novembro (147 DAC) até o final do experimento em abril (300 DAC). 
Figura 9. Dados médios (A) e curva de regressão (B) referente a massa úmida (g) das folhas senescente da cana soca, SP81-3250. Cajuru, SP.

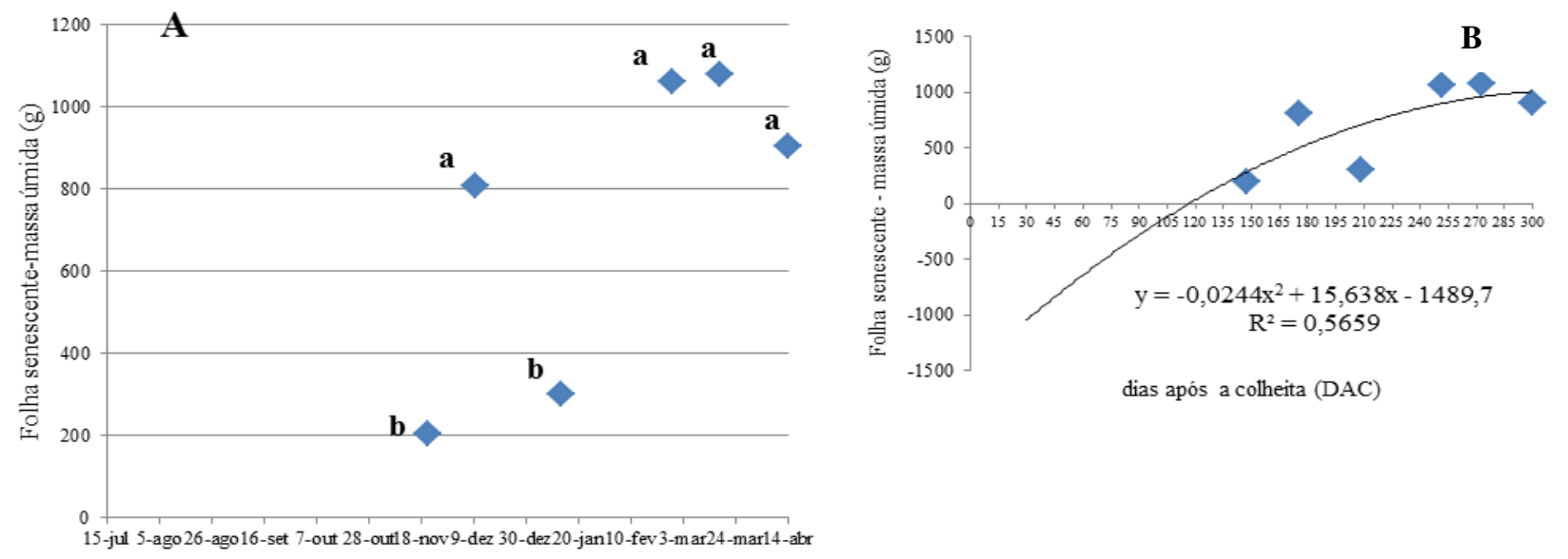

Fonte: Elaborado pelo autor

Figura 10. Dados médios $(\mathrm{A})$ e curva de regressão $(\mathrm{B})$ referente à massa seca $(\mathrm{g})$ das folhas senescente da cana-soca, SP81-3250. Cajuru, SP.
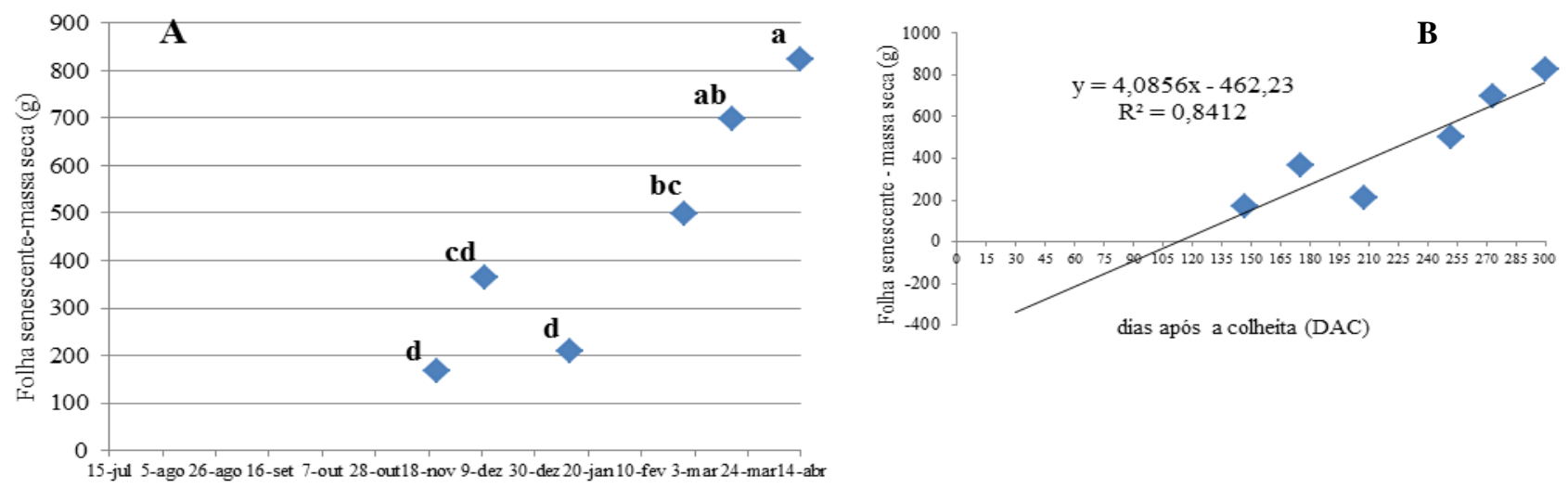

Fonte: Elaborado pelo autor

Pelos valores de massa fresca das folhas totais (Figura 11), observa-se um formato sigmoide na curva, em que o ganho de massa foi aumentando de modo mais lento em julho e agosto (no início do crescimento da cultura, que coincidiu com condições ambientais mais restritivas) e de modo mais rápido de setembro até dezembro (meses de fatores climáticos favoráveis) e estabilizando-se nos meses subsequentes ensaiando ligeira queda em abril, quando as condições tornam-se novamente mais restritivas.

Figura 11. Dados médios (A) e curva de regressão (B) referente à massa fresca $(\mathrm{g})$ das folhas totais em 1 m linear da cana-soca, SP81-3250. Cajuru, SP.
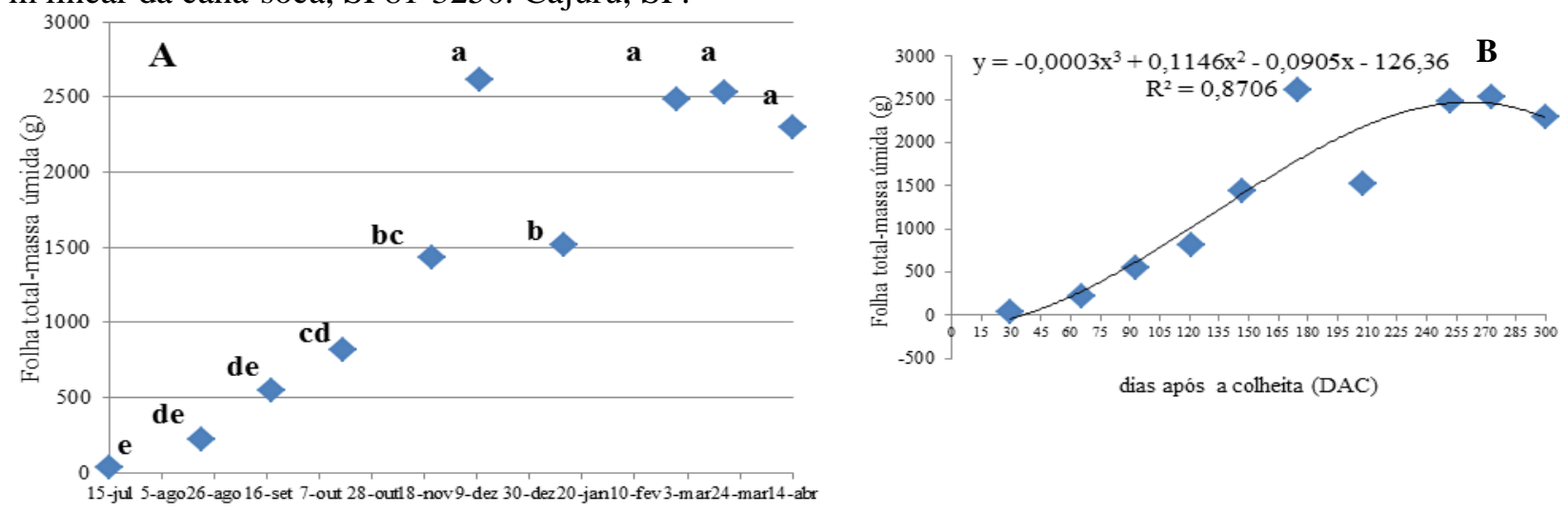

Fonte: Elaborado pelo autor 
Os valores de massa seca das folhas totais (Figura 12) apresentou comportamento semelhante à Figura 11 (massa úmida), mas nesse caso, uma regressão linear ajustou-se bem a curva de crescimento da massa seca das folhas totais, demonstrando ganho de massa seca durante toda avaliação.

Figura 12. Dados médios $(\mathrm{A})$ e curva de regressão $(\mathrm{B})$ referente à massa seca $(\mathrm{g})$ das folhas totais da cana-soca, SP81-3250. Cajuru, SP.
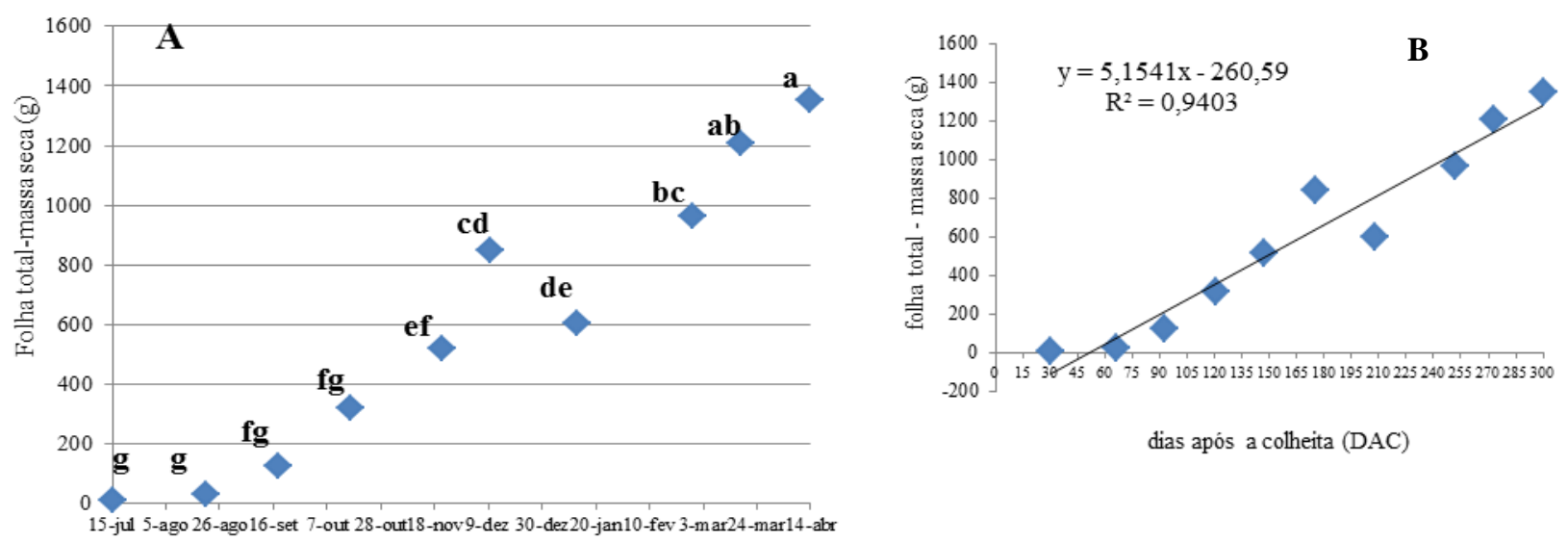

Fonte: Elaborado pe

Observa-se que o crescimento em comprimento da folha +3 é mais lento no inicio do crescimento da cultura e após condições mais adequadas de clima, aumentou rapidamente e permaneceu constante até o final do experimento estabelecendo-se em torno de 1,5 a 1,7m (Figura 13). O comprimento da folha de cana-de-açúcar na fase adulta pode variar de $0,5 \mathrm{~m}$ e chegar a $1,5 \mathrm{~m}$, segundo de Scarpari e Beauclair (2008), dados semelhantes aos verificados nesse experimento.

Figura 13. Dados médios (A) e curva de regressão (B) referente ao comprimento da folha $+3(\mathrm{~cm})$, da cana-soca, SP81-3250. Cajuru, SP.
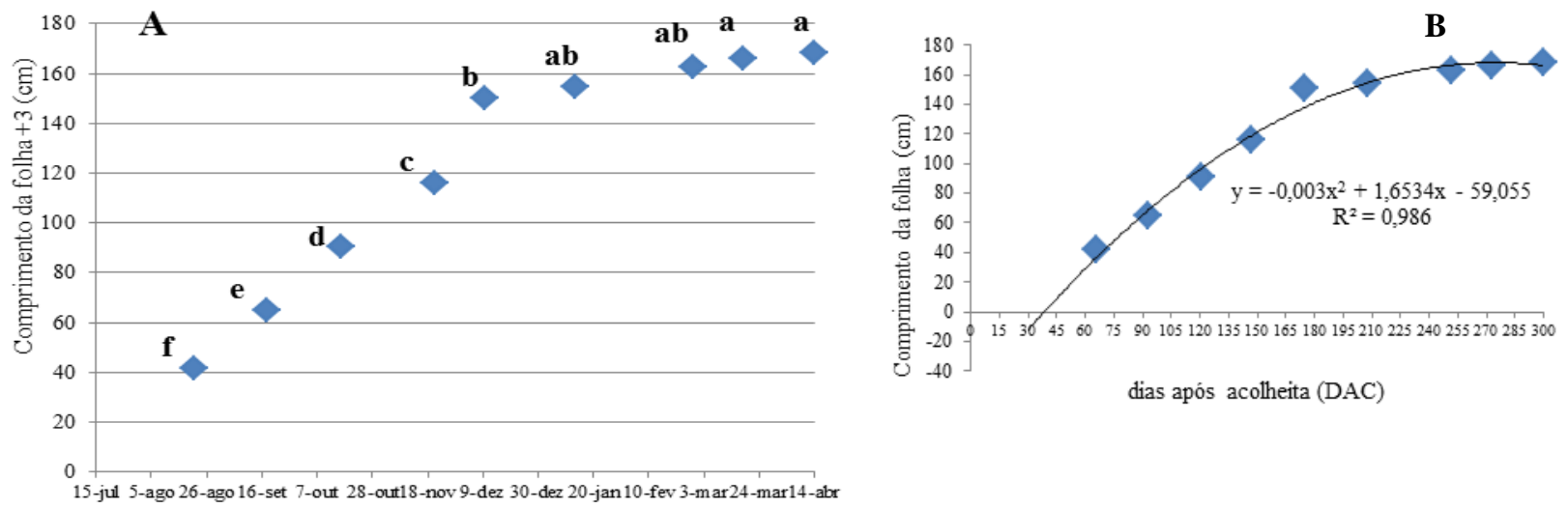

Fonte: Elaborado $p$

A Figura 14 representa a largura da folha +3 em que esta desenvolve-se lentamente até outubro e rapidamente de novembro a fevereiro, estabilizando-se em março e abril em torno de $4,5 \mathrm{~cm}$. A largura da folha de cana-de-açúcar na fase adulta pode variar de $2,5 \mathrm{~cm}$ e chegar a $10 \mathrm{~cm}$, segundo de Scarpari e Beauclair (2008) sempre na dependência da variedade. Nesse caso, a curva verificada de crescimento em largura da folha +3 é também sigmoidal. 
Figura 14. Dados médios (A) e curva de regressão (B) referente à largura $(\mathrm{cm})$ da folha +3 , da cana-soca, SP81-3250. Cajuru, SP.
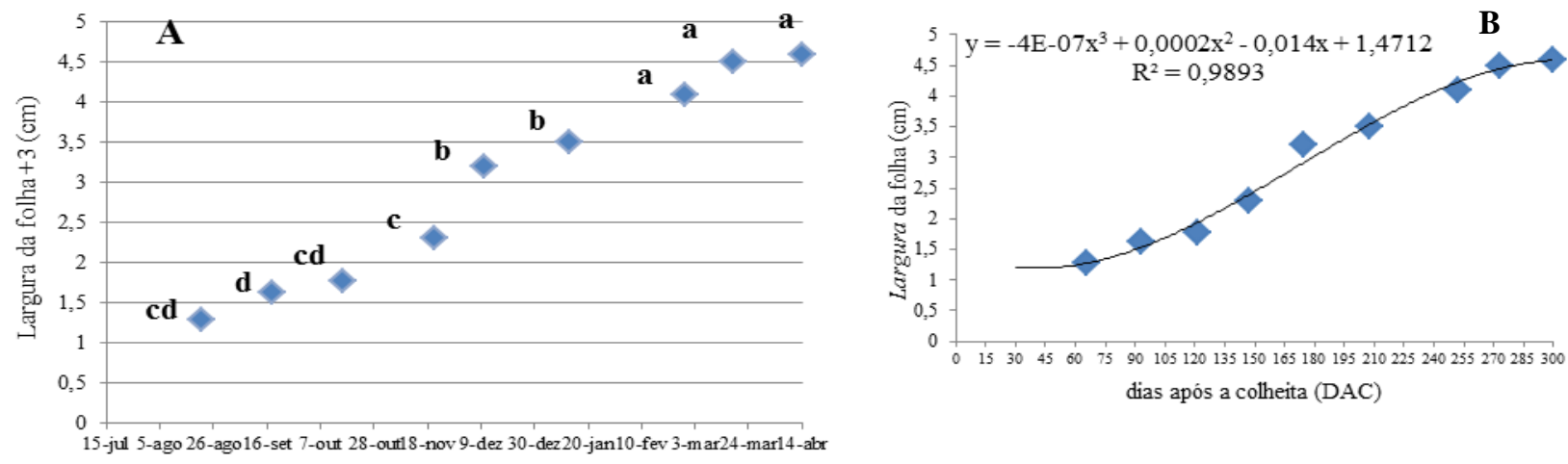

Fonte: Elaborado pelo autor

A área foliar (Figura 15) cresceu lentamente no início do ciclo (agosto/setembro), coincidindo com os meses de menor precipitação. De fato, fatores como períodos de estresse hídrico causam a diminuição da área foliar (INMAM-BAMBER, 2004). De acordo com Maule; Mazza e Martha Jr (2001), a disponibilidade de água no solo governa a produção vegetal, sendo que sua falta ou seu excesso afeta de maneira significativa o desenvolvimento da área foliar da cana-de-açúcar. Ao iniciar o período de maiores precipitações e temperaturas (Figura 2) houve um aumento significativo na área foliar (Figura 15) até o mês de dezembro, porém não houve diferença estatística na área foliar a partir de novembro até abril. Segundo Chang (1968), o ideal é que o índice de área foliar (IAF) ocorra sob condições climáticas satisfatórias à fotossíntese. Miocque (1999) e Ido (2003) relatam que o período de maior crescimento da área foliar pode ser observado entre os meses de dezembro a março. Fato verificado também no experimento. Portanto, o pico em área foliar nesse experimento (Figura 15) ocorreu aos seis meses de idade da cana-soca, mas permaneceu estável até o final do experimento. Tais dados concordam com Gascho e Shih (1983) que com relação ao IAF, notaram que o valor máximo para essa cultura foi alcançado aos seis meses de idade. $\mathrm{O}$ aumento do IAF prenuncia alta produção de fotossintatos e de açúcares.

Figura 15. Dados médios (A) e curva de regressão (B) referente à área foliar $\left(\mathrm{cm}^{2}\right)$ da cana-soca, SP813250. Cajuru, SP.
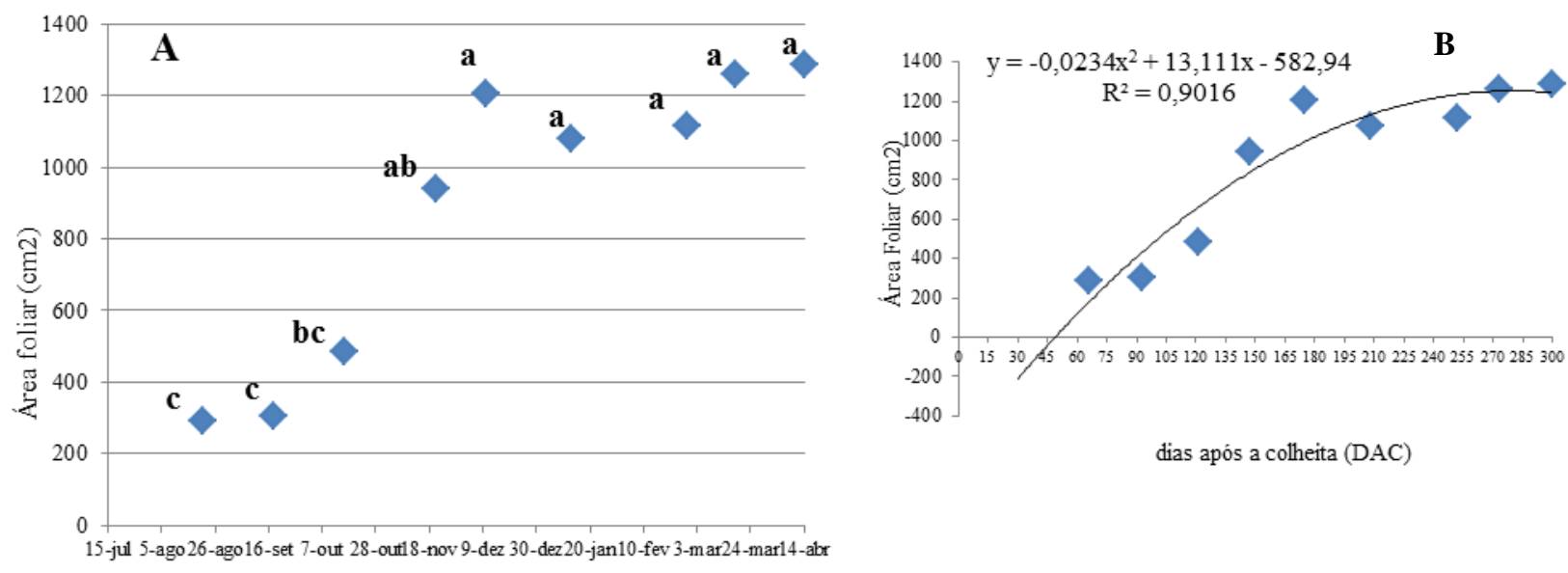

Fonte: Elaborado pelo autor 
A curva de área foliar descrita nesse ensaio é típica e corrobora o relato de Machado et al. (1982) em que no início do ciclo da cultura o IAF é pequeno. Nessa fase, apresenta um crescimento lento, aumentando, rapidamente, até atingir um valor máximo. A partir daí permanece, praticamente, constante ou pode diminuir em condições climáticas desfavoráveis. O aumento do IAF ocorre em função tanto do aumento do número de folhas por colmo, como do aumento da área foliar individual.

No ensaio, em julho e agosto (Figura 16) praticamente não houve colmo para efetuar as mensurações, isso por se tratar do início do crescimento da planta sob condições restritivas do ambiente de condução do experimento. Porém, com condições mais adequadas de precipitações e temperaturas no mês de novembro (147 DAC) houve um aumento significativo na massa do colmo até o final da avaliação da cultura (300 DAC). De acordo com Cesnik e Miocque (2004), para cana de ano e meio, em São Paulo, as pesagens devem ser iniciadas somente em junho, em virtude do pequeno desenvolvimento da planta, nesse período inicial de vegetação. A partir de então, as pesagens devem ser feitas mensalmente. No experimento a cana-soca foi colhida em junho o que explica a baixa formação de colmos até que as condições de umidade e temperatura fossem mais propícias ao crescimento da cana-soca, além disso, com o final da fase de intenso perfilhamento (em dezembro- Figura 3), os perfilhos que sobreviveram a essa fase de alta competição intraespecífica cresceram, ganhando massa.

Figura 16. Dados médios (A) e curva de regressão (B) referente à massa fresca $(\mathrm{g})$ do colmo dos perfilhos de cana-soca, SP81-3250. Cajuru, SP.
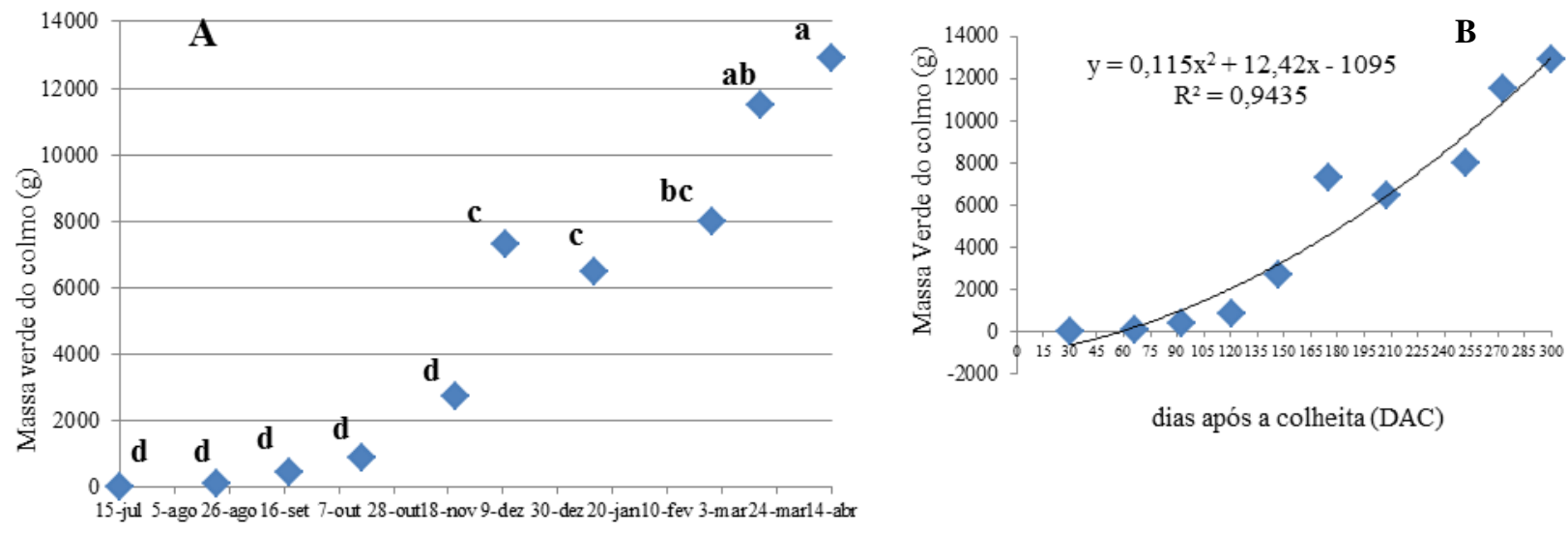

Fonte: Elaborado pelo autor

Pelos valores de massa seca do colmo (Figura 17) observa-se, a semelhança da matéria fresca, o crescimento mais lento até outubro (121 DAC), e, em condições mais adequadas de precipitações e temperaturas (a partir de novembro) houve um aumento na massa seca do colmo até o mês de fevereiro (252 DAC). Em março e abril o crescimento tendeu a ser mais lento, embora continuasse a ocorrer. A curva de crescimento descrita pela massa seca dos colmos (Figura 17) é uma curva sigmoide, em que se verifica uma fase inicial mais lenta, seguida de um pico que coincide com época de alta umidade e temperatura, havendo posteriormente crescimento lento, quando se inicia condições ambientais mais restritivas ao crescimento, dados que corroboram os verificados por Machado et al. (1982). 
Figura 17. Dados médios (A) e curva de regressão (B) referente à matéria seca (g) do colmo da cana-soca, SP81-3250. Cajuru, SP.
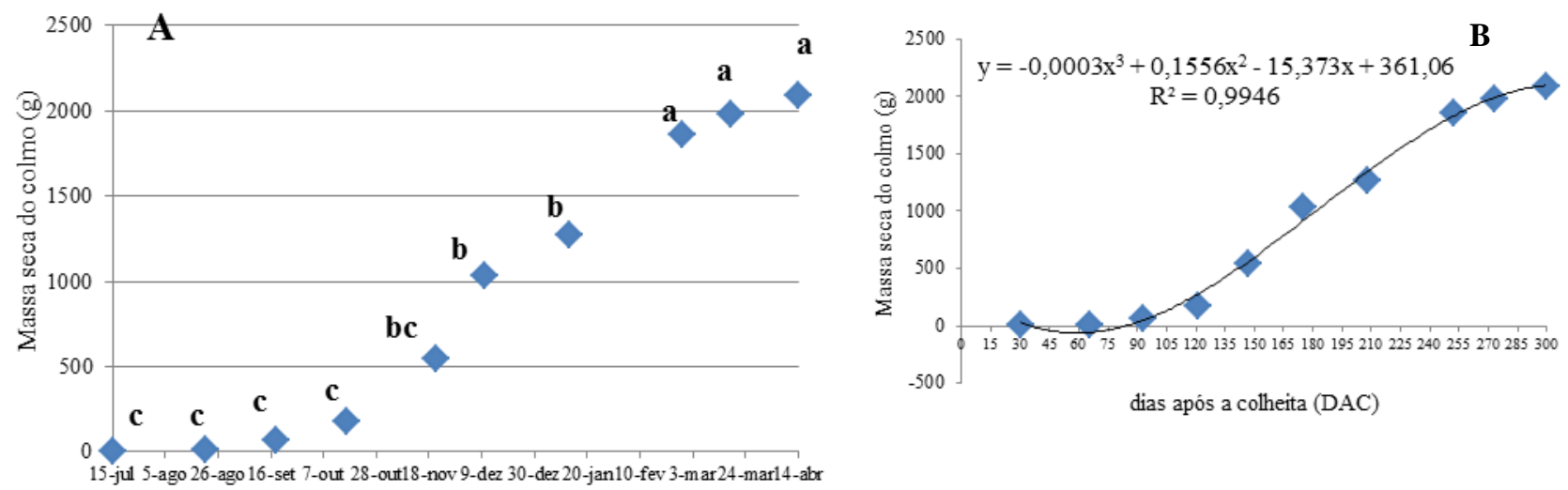

Fonte: Elaborado pelo autor

Na Tabela 3 estão representados os dados fornecidos pela Usina ao produtor sobre a cana colhida referente à área de 2,51 hectares em que foi implantado o experimento.

Tabela 3. Dados do relatório fornecido ao proprietário, pela usina, da cultura da cana-de-açúcar do talhão em que foi alocado o ensaio sobre crescimento da cana-soca. Mococa/SP.

\begin{tabular}{ll}
\hline Dados da usina & Valores \\
\hline Produtividade estimada e real - tonelada de cana por hectare (TCH) & 90,0 e 85,3 \\
Teor de sacarose (\%) - POL corrigida (PC) & 14,31 \\
Pureza (\%) & 83,73 \\
ATR (kg de açúcar recuperado por tonelada de cana) & 142,20 \\
Tonelada de POL por hectare (TPH) & 28,42 \\
Tempo de queima (h) & 27,10 \\
Fibra (\%) & 12,49 \\
\hline
\end{tabular}

Fonte: Elaborado pelo autor

A estimativa de produtividade calculada no ensaio foi de 100,1 t.ha ${ }^{-1}$, esse valor está mais próximo ao estimado pela usina $\left(90\right.$ t.ha $\left.^{-1}\right)$, do que do real obtido $\left(85,3\right.$ t.ha $\left.{ }^{-1}\right)$. Isso provavelmente ocorreu devido à altura mensurada do colmo, pois nos dados do ensaio, não se fez o desponte comum na prática, e, que pode ser até maior quando a cana é colhida precocemente como ocorrido no ensaio. Isso se justificaria, pois como ainda o ponteiro não está rico em sacarose, com maior desponte reduz-se o frete, já que no caso, a distância era superior a $30 \mathrm{Km}$ da usina ao proprietário. $\mathrm{O}$ valor 85 t.ha $^{-1}$ na primeira soca (Tabela 3) foi bom para o ambiente restritivo (Tabela 1 e 2) que se implantou essa variedade aliado à colheita precoce da mesma. Pelas curvas de crescimento, principalmente as de colmo há percepção de que o crescimento ainda existia e que a cana poderia ainda acumular pouco mais de matéria seca (Figura 17). Contudo em função do ambiente edafoclimático restritivo, o acúmulo de sacarose (Pol \% Cana: $\mathrm{PC}=14,31 \%$ - Tabela 3) se dá mais precocemente e está dentro do preconizado para início de safra. Deuber (1988) afirma que a cana-de-açúcar torna-se madura no momento em que apresenta um teor mínimo de PC acima de 13\%. Segundo Fernandes (2000), para o Estado de São Paulo, uma cana para ser considerada madura deve apresentar PC variando de 14,4 - 15,3\%. Portanto, a variedade estaria apta à colheita, e aguardar, normalmente, não gera ganho em toneladas de cana por hectare $(\mathrm{TCH})$ nesse tipo de ambiente restritivo ao crescimento e poderia prejudicar a brotação da próxima soca, pois se trata ainda de primeira soca, em que o sistema radicular ainda não se desenvolveu plenamente, assim se considera uma 
estratégia assertiva da usina.

\section{CONCLUSÃO}

Conclui-se para o canavial de segundo corte da 'SP81-3250', locado em ambiente edáfico restritivo e colhido em 15 de junho (300 dias após colheita) que:

O número de perfilhos por metro linear atingiu um máximo de 27,3 em outubro (quatro meses após colheita), mas pela competição intraespecífica por elementos do meio apenas 9,8 perfilhos por metro linear geraram colmos industrializáveis.

O padrão de crescimento da parte aérea da maioria dos parâmetros avaliados coincide com curva sigmoide, em que o crescimento da parte aérea inicialmente é lento e passa a ser acelerado, com condições de maior precipitação e temperatura, com tendência a estabilizar-se ou crescer mais lentamente, com a chegada novamente de condições ambientais mais restritivas ao crescimento.

A estimativa de produção de colmos por hectare $(\mathrm{TCH})$ usada superestimou a produtividade real pelo não desponte do colmo.

\section{REFERÊNCIAS}

ALVAREZ, I.A.; CASTRO, P.R.C.. Crescimento da parte aérea de cana crua queimada. Scientia Agrícola. v.56, n.4, out./dez. Suplemento. 1999. p.1069- 1079.

ARIZONO, H. Variedade de cana-de-açúcar. Bula 2003. Disponível em: http://www.agencia.cnptia.embrapa.br/gestor/cana-de açucar/arvore/CONTAG01_42_1110200717570.html. Acesso em: 07 dez. 2010.

BARBOSA, M.H.P.et al. Análise de causa e efeito para produção de colmos e seus componentes na seleção de famílias de cana-de-açúcar. In: CONGRESSO NACIONAL DA STAB, 8. 2002. Recife: Pernambuco. Anais... 2002. p.366-370.

BENINCASA, M.M.P. Análise de crescimento de plantas: noções básicas. Jaboticabal, FUNEP, 1988. $44 \mathrm{p}$.

BENINCASA, M.M.P. Análise de crescimento de plantas: noções básicas. Jaboticabal: FUNEP, $2003.41 \mathrm{p}$.

BERTON, G.H. Análise de crescimento e produtividade de sete clones de cana-de-açúcar, em canasoca, cultivados no Município de Paranavaí-PR. 2014. 67f. Dissertação (Mestrado em Produção Vegetal) - Universidade Federal do Paraná, Curitiba, 2014.

BIDOIA, M.A.P.; BIDOIA, M.A.P. Instalação e colheita de experimentos. In: DINARDO-MIRANDA, L.L. ; VASCONCELOS. A.C.M.; LANDELL. M.G.A. Cana-de-açúcar. Campinas - SP. Instituto Agronômico - IAC. 2008.p.821-838.

BRUNINI, O.et al. Zoneamento de culturas bioenergéticas no Estado de São Paulo: aptidão edafoclimática da cana-de-açúcar. Campinas: IAC, 31p, 2008.

CÂMARA, G.M.S. Ecofisiologia da cultura da cana-de-açúcar. In: CÂMARA, G.M.S. Produção da cana-de-açúcar. ESALQ: Piracicaba, 1993.p.31-64. 
CAMARGO, A.P.; ALFONSI, R.R., PINTO, H.S.; CHIARINI, J.V. Zoneamento de aptidão climática para culturas comerciais em áreas de cerrado. In: Simpósio sobre o Cerrado: bases para a utilização agropecuária, 4. Anais... Belo Horizonte, Ed. Itatiaia, São Paulo, EDUSP, 1977, p.89-105.

CASAGRANDE, A.A. Tópicos de morfologia e fisiologia da cana-de-açúcar. Jaboticabal: FUNEP, 1991. 157p.

CESNIK. R.; MIOCQUE. J. Melhoramento da cana-de-açúcar. Brasília - DF. Empresa Brasileira de Pesquisa Agropecuária Embrapa Meio Ambiente. 2004.307p.

CHANG, J. Climate and agriculture: in ecological survey. Chicago, Aldine, 1968, 304p.

CIVIERO, J.C. Arranjo de plantas em cana-de-açúcar: comportamento do sistema radicular, análise de crescimento, componentes morfológicos e de produção. Curitiba: Universidade Federal do Paraná, 2014. 192f. Tese (Doutorado) - Universidade Federal do Paraná, Curitiba, 2014.

CIIAGRO. Centro integrado de informações agrometeorológicas. Resenha Cajuru. Disponível em: http://www.ciiagro.sp.gov.br/ciiagroonline/Listagens/Resenha/LResenhaLocal.asp. Acesso em: 04 ago. 2017.

DEUBER, R. Maturação da cana-de-açúcar na região sudeste do Brasil. In: SEMINÁRIO DE TECNOLOGIA DA COPERSUCAR, 1988. Piracicaba. Anais... Piracicaba: Copersucar, 1988. p. 33-40.

DUARTE, A.M.A. Crescimento e maturação da cana-de-açúcar, sob condições de cultivo irrigado, em Janaúba-MG. 2009.41f. Dissertação (Mestrado em Produção Vegetal no Semiárido) - Universidade Estadual de Montes Claros, Janaúba, MG. 2009.

FERNANDES, A. C. Cálculos na Agroindústria da cana de açúcar. Piracicaba, STAB: Açúcar, Álcool e Subprodutos, 2000, 193p.

GASCHO, G.J.; SHIH, S.F. Sugarcane. In: TEARE, I.D.; PEET, M.M. (Ed). Crop water relations. New York: John Wiley, 1983. p.445-479.

GLASZIOU, K.T.; BULL, T.A.; HATCH, M.D.; WHITEMAN, P.C. Physiology of sugar cane. VII. Effects of temperature, photoperiod duration, and diurnal and seasonal temperature changes on growth and ripening. Australian Journal of Biological Sciences, East Melbourne, v.18, p.53-66, 1965.

HERMANN, E.R.; CÂMARA, G.M.S. Um método simples para estimar a área foliar de cana-de-açúcar. Revista STAB, v.17, p.32-34, 1999.

HESKETH, J.; BAKER, D. Light and carbon assimilation by plants communities. Crop Science. v.7, p.285-93. 1967.

IDO, O.T. Desenvolvimento radicial e caulinar, de três variedades de cana-de-açúcar, em Rizotron, em dois substratos. Curitiba: 2003. 141f. Tese (Doutorado em Agronomia, Produção Vegetal) -

Universidade Federal do Paraná. 2003.

IMNAM-BAMBER, N.G. Sugarcane water stress criteria for irrigation and drying off. Field Crops Research, v.89, p.107-122, 2004.

IRVINE, J.E. Relations of photosynthetic rates and leaf and canopy characters to sugarcane yield. Crop Science, v.15, p.671-676. 1975.

LANDELL, M.G.A.; SILVA, M.A. Manual do experimentador: melhoramento da cana-de-açúcar. In: Metodologia de Experimentação: ensaios de competição em cana-de-açúcar. Pindorama: Instituto Agronômico, 1995. Não paginado. (Apostila de Treinamento Interno). 
LEME, E.J.A.; MANIERO, M.A.; GUIDOLIN, E.J.C. Estimativa da área foliar da cana-de-açúcar e sua relação com a produtividade. Cadernos Planalsucar, v.2, p.3-22. 1984.

JAMES, N.I. Yeld components in random and selected sugarcane populations. Crop Science, v.11, p.906908, 1971.

MACHADO, E.C. Fisiologia de produção de cana-de-açúcar. In: Cana-de-açúcar: cultivo e utilização. Campinas: Fundação Cargill, 1987. p.56-87.

MACHADO E.C.et al.Índices biométricos de duas variedades de cana-de-açúcar. Pesq. Agropec. Bras. , v.17, n.9, p.1323-1329, 1982.

MACHADO, E. C. Um modelo matemático-fisiológico para simular acúmulo de massa seca na cultura de cana-de-açúcar (Saccharum spp.). 1981. 115 f. Dissertação (Mestrado em Biologia) Instituto de Biologia, Universidade Estadual de Campinas, Campinas, 1981.

MARAFON, A.C. Análise Quantitativa de Crescimento em Cana-de-Açúcar: uma Introdução ao Procedimento Prático. Aracaju, EMBRAPA, 2012. 29 p. (Documentos, 168).

MARIOTTI, J.A. Associations among yield and quality components in sugarcane hybrid progenies. In: CONGRESS OF THE INTERNATIONAL SOCIETY OF SUGAR CANE TECNOLOGISTS, 14, New Orleans, 1971. Proceedings... New Orleans: ISSCT, p. 177- 184, 1971.

MAULE, R.F.; MAZZA, J.A.; MARTHA JR, G.B. Produtividade agrícola de cultivares de cana-de-açúcar em diferentes solos e épocas de colheita. Scientia Agricola, v. 58, n.2, p.295-301, abr./jun. 2001.

MIOCQUE, J. Avaliação de crescimento e de produtividade de matéria verde da cana-de-açúcar na região de Araraquara - SP. Revista da STAB. Piracicaba, v.17, n.4, p.45-47, 1999.

NOGUEIRA, R. C.et al. Bases do crescimento e desenvolvimento vegetal. In: PAIVA, R.; OLIVEIRA, L. M. Fisiologia e Produção Vegetal. Lavras: Editora UFLA, 2006. p. 17-29.

OLIVEIRA, R. A. De. Análise de crescimento da cana-de-açúcar, na região noroeste do Paraná. Curitiba. 2004. 65 f. Dissertação (Mestrado). Universidade Federal do Paraná. 2004.

OLIVEIRA, R.A.et al. Crescimento e desenvolvimento de três cultivares de cana-de-açúcar, em canaplanta, no Estado do Paraná: taxas de crescimento. Scientia Agraria, v.6, n.1-2, p.85-89, 2005.

PRADO, A.P.A. Perfilhamento e produção da cana-de-açúcar (Saccharum spp.) em função da densidade de plantio. 1988. 69f. (Dissertação de Mestrado) - Escola Superior de Agricultura Luiz Queiroz. Universidade de São Paulo. Piracicaba, 1988.

RAIJ, B. van; CANTARELLA, H.; QUAGGIO, J.A.; FURLANI, A.M.C. (Ed.). Recomendações de adubação e calagem para o Estado de São Paulo. 2.ed. Campinas: Instituto Agronômico/Fundação IAC, 1997. 285p. (Boletim Técnico, 100).

RAMESH, P.; MAHADEVASWAMY, M. Effect of formative phase drought on different classes of shoots, shoot, mortality, cane attributes, yield and quality of four sugarcane cultivars. Journal Agronomy \& Crop Science, v.185, p.249-258, 2000.

RESENDE. M.; CURI. N. E SANTANA. D.P. Pedologia e Fertilidade do solo: Interpretações e aplicações. Brasília - DF. MEC-ESAL-POTAFÓS. 1988. 81p.

ROCHA, A.M.C.. Emergência, perfilhamento e produção de colmos de cana-de-açúcar (Saccharum spp.) em função das épocas de plantio no Estado de São Paulo. 1984. 154f. Dissertação de Mestrado Escola Superior de Agricultura Luiz Queiroz. Universidade de São Paulo. Piracicaba, 1984. 
RODRIGUES, J. D. Fisiologia da cana-de-açúcar. Botucatu, Universidade Estadual Paulista Instituto de Biociência, 1995. 75p.

SANTOS, V.R. Crescimento e produção de cana-de-açúcar em diferentes fontes de fósforo. Rio Largo, 2006. 88f. Dissertação (Mestrado em Agronomia: Produção Vegetal) - Universidade Federal de Alagoas. Centro de Ciências Agrárias. 2006.

SCARPARI, M.S; BEAUCLAIR, E.G.F. Anatomia e botânica. In: DINARDO-MIRANDA, L.L. ; VASCONCELOS. A.C.M.; LANDELL. M.G.A. Cana-de-açúcar. Campinas - SP. Instituto Agronômico - IAC. 2008.p. 47-56.

SEGATO, S.V.; MATTIUZ, C.F.M.; MOZAMBANI, A.E. Aspectos fenológicos da cana-de-açúcar. In: SEGATO, S.V.; PINTO, A.S.; JENDIROBA, E. Atualização em produção de cana-de-açúcar. Piracicaba: : CP 2, 2006. p.19-36.

SILVA, M.A.; CATO, S.C.; COSTA, A.G.F. Produtividade e qualidade tecnológica da soqueira de canade-açúcar submetida à aplicação de biorregulador e fertilizantes líquidos. Ciência Rural, v.40, n.4, p.774$780,2010$.

SINCLAIR, T.R.et al. Sugarcane leaf area development under field conditions in Florida, USA. Field Crops Research, v. 88, p. 171-178, 2004.

STATSOFT. Statistical, data analysis software system, v.8. Disponível em: <http://www.statsoft.com>, 2007. Acesso em: 10 nov. 2010.

SUGUITANI, C. Entendendo e a produção de cana-de-açúcar: avaliação do modelo Mosicas. 2006. 60 f. Tese (Doutorado em Fitotecnia) - Escola Superior de Agricultura "Luiz de Queiroz" Universidade de São Paulo, Piracicaba, 2006.

TERAUCHI, T.; MATSUOKA, M. Ideal characteristics for the early growth of sugarcane. Japanese Journal of Crop Science. Japan, v.69, n.3, p.286-292, 2000.

TERAUCHI T.et al. Comparison of the early growth between sugarcane and sweet sorghum. Japanese Journal of Crop Science. Japan, v.68, n.3, p.414-418, 1999.

TERUEL, D. A.; BARBIERE, V.; FERRARO JÚNIOR, L. A. Sugarcane leaf area index modeling under different soil water conditions. Scientia Agrícola, v.54, p.93-44, 1997.

TOKESHI, H. Perfilhamento e perdas pelo carvão da cana-de-açúcar. STAB, Piracicaba, v.4, n.5, p.34-44, 1986.

VAN DILLEWIJN, C. Botany of sugarcane. Waltham: Chronica Botanica Co., 1952. $371 \mathrm{p}$.

WAHID, A. Analysis of toxic and osmotic effects of sodium chloride on leaf growth and economic yield of sugarcane. Botanical Bulletin of Academia Sinica, v.45, p.133-141, 2004.

WATSON, D.J. Comparative physiological studies on the growth of field crops. I variation in net assimilation rate and leaf area between species and varieties, and within between years. Annals of Botany, v.11, n.41, 1947.

WILHELM, W.W.; McMASTER, G.S. Importance of the phyllochron in studying development and growth in grasses. Crop Science, Madison, v. 35, n.1, p. 1-3, 1995. 